\title{
Rheometry of silts of Fodda Wadi dam in relation to their transport and their valorization
}

\author{
N.-E. Boudjenane ${ }^{1}$, M. Mekkaoui ${ }^{1}$, M. Belhadri ${ }^{1}$, L. Abdelkrim ${ }^{1}$ \\ \& A. Magnin ${ }^{2}$ \\ ${ }^{1}$ Laboratory LRTTFC, Department of Hydraulic, \\ Technical University of Oran, Oran, Algeria \\ ${ }^{2}$ Laboratory of Rheology, INPG, UJF, CNRS ULR, Grenoble, France
}

\begin{abstract}
Silting of dams is an important economic concern in Algeria. This phenomenon considerably reduces the capacity of water reserves. The control of hydraulics and unsilting techniques, as well as the valorization of collected silts, pass by the rheometric comprehension of their behavior and the relationships to their physicochemical characteristics. For this purpose, five samples taken at selected places at the reserve of the Fodda Wadi dam will be studied. A granulometric study shows that we are in the presence of a mud whose particle size varies between 0,1 and $40 \mu \mathrm{m}$ and whose argillaceous fraction is about $50 \%$. A study of the potential zeta of the silts shows a stability zone for $\mathrm{pH}$ between 6 and 10 . Flow yield stress, which is a very important characteristic in unsilting of dams was studied. The effects of volumetric concentration, of $\mathrm{pH}$ and rest period on the flow yield stress, were studied. The yield stress increases considerably with the volumetric fraction. Scale laws according to concentration and sampling places are identified. A correlation is established between the evolution of the yield stress of flow and the evolution of the $\mathrm{pH}$. Flow properties of the silts were studied on a wide range of shearing speed. An important preliminary work to control the disturbing effects (sedimentation, fracturing, etc) of rheometric characterization was carried out. Several geometries of measurements and visualizations of deformation fields were implemented. The influence of the concentration of the dry matter is presented.

Keywords: silt, dam, rheometry, granulometry, yield stress.
\end{abstract}




\section{Introduction}

Algeria is engaged in a large construction program of dams of great capacity. This program should allow the mobilization of 8,3 billion cubic meters in 2010 . It is imperative with these achievements to simultaneously prevent and fight against hydrous erosion on the one hand and on the other hand to find the means and solutions for the unsilting of dams affected by the phenomenon of silting. It is important to preserve the useful volume of water storage in the reserve which is exploited in various fields of the national economy, such as drinking water supply, agriculture and industry. This crucial phenomenon considerably reduces the water capacities of reserves (Migniot [1] and Belhadri [4]).

The silting represents a major problem in Algeria, where more than $50 \%$ of dams are silted. Actually, silts of certain dams are rejected at the downstream of dams during unsilting by hydraulic means. This is the origin of enormous problems like filling of the river and ecological disasters, such as the case of Macta of Marsa El-Hadjadj in Western Algerian during the unsilting of the dam Fergoug in 1985-1986. The control of unsilting techniques, as well as the valorization of eroded silts, pass by the rheometric comprehension of the behavior of the silts and the relationships to their physicochemical characteristics.

Muds and silts are characterized by complex rheological behaviors (Ayadi [5], Benna et al [6], Coussot and Piau [8]): yield stress of flow, plasticity, thixotropy, rheofluidification. These rheological properties are controlled by the nature of clays, the physicochemical parameters $(\mathrm{pH}$, ionic force, natural of ions, etc) and the presence of polymers (Delgado et al [11], Migniot [12], Pignon [13]).

In addition, these rheological properties play a fundamental role on the flows and the performances of transport techniques (Périgaud [2], Belhadri [9], Coussot [14]), like linear and singular energy losses, zones of non-flow, recirculation, starting times, etc.

The heterogeneous nature of these fluids and the particular interactions on a macroscopic scale are the source of highly nonlinear properties of volume, but also of fluid-wall interaction properties, which must be integrated in the comprehension of the phenomena (Magnin and Piau [3], Cousot and Boyer [7], Coussot [14]). Some important progress has been made in the last few years on the rheology of silts and muds (Migniot [1], Belhadri [4,10], Coussot and Boyer [7], Coussot and Piau [8], Belhadri [9]), but the rheological behavior of flows always remains a little exploited field, due to the complexity of the material structure.

In this study, we are interested in unsilting of the dam Fodda Wadi by hydraulic means and in valorization of his mud. The physicochemical properties, the zetametry, the yield stress of flow per scissometry, which is a very important characteristic to erode and to flow material in conduits will be particularly studied, as well as the silt's flow on a wide range of shearing speeds on Weissenberg rheometer using several different geometries (cone-plan, coaxial). 
Precautions were taken to avoid disturbing phenomena of flows, such as the slip with the wall, the evaporation, the fracturing, the digging and the sedimentation. The results are presented and discussed.

\section{Samples and their physicochemical characterization}

\subsection{Types of samples}

The silt studied comes from the Fodda Wadi dam, which is located at the western north of Algeria in Wilaya of Chlef on the wadi, whose dam bears the name, it is located at approximately of $10 \mathrm{~km}$ upstream of the village El-Karimia (Ex: Lamartine), at the entry of the throats of Djebel Akb and Mali (figure 1).

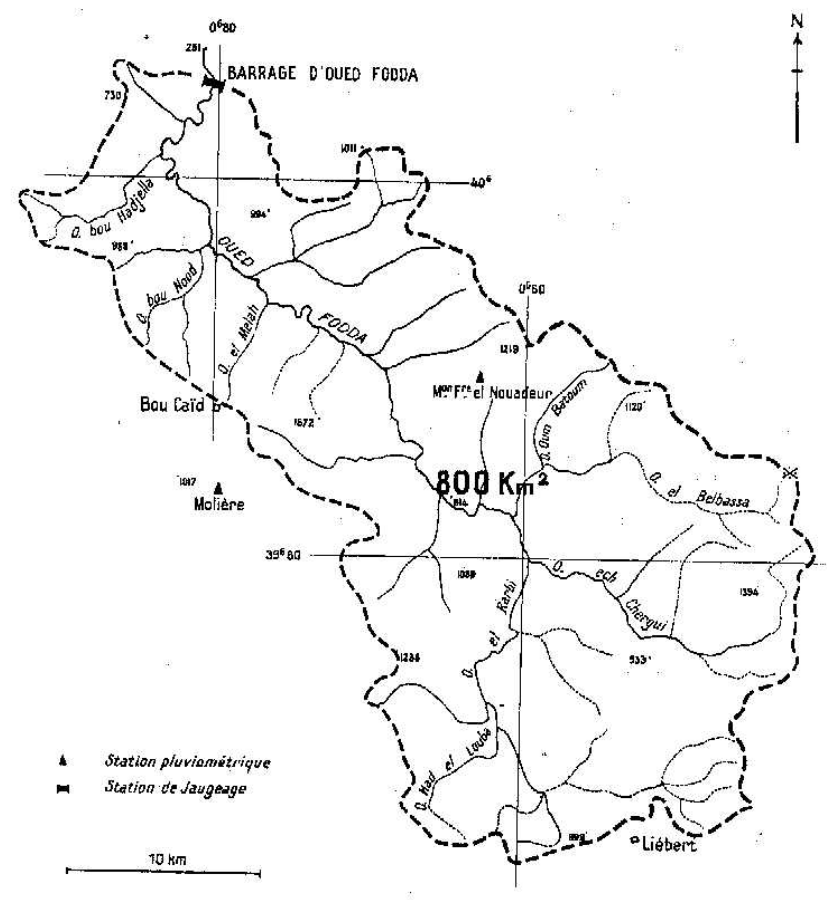

Figure 1: $\quad$ Situation of the Fodda Wadi dam.

Five samples were taken from the dam at various places of reserve. Their sampling distances are respectively 1; 120; 1400; 5000 and 8000 meters from the dam, taking care of the test sample selections, of the sampling places and of their transport to the laboratory.

\subsection{Physicochemical properties of the samples}

The density of the five samples is on average 2,5. Their content in natural water is around $45 \%$ for four samples, and $55 \%$ for the fifth sample. The $\mathrm{pH}$ for the five samples is about 7,5 which is close to neutral (table 1). 
Table 1: $\quad$ Physicochemical properties of five samples.

\begin{tabular}{|c|c|c|c|c|c|c|c|}
\hline Sample & $\begin{array}{c}\mathrm{d}_{50} \\
(\mu \mathrm{m})\end{array}$ & $\begin{array}{c}\text { Clay } \\
\text { fraction } \\
(\%)\end{array}$ & $\begin{array}{c}\text { Sand } \\
\text { fraction } \\
(\%)\end{array}$ & $\begin{array}{c}\text { Position } \\
\text { / dam } \\
(\mathrm{m})\end{array}$ & Density & $\begin{array}{c}\text { Water } \\
\text { fraction } \\
(\%)\end{array}$ & $\mathrm{pH}$ \\
\hline 1 & 2,39 & 64,6 & 0,0 & 1,00 & 2,50 & 44,1 & 7,52 \\
\hline 2 & 4,55 & 46,5 & 0,0 & 120 & 2,43 & 44,9 & 7,75 \\
\hline 3 & 5,07 & 42,8 & 6,0 & 1400 & 2,54 & 54,4 & 7,50 \\
\hline 4 & 3,45 & 53,1 & 1,9 & 5000 & 2,35 & 42,2 & 7,32 \\
\hline 5 & 3,59 & 59,0 & 0,7 & 8000 & 2,69 & 43,8 & 7,50 \\
\hline
\end{tabular}

For the granulometric analysis, the samples were studied by putting at the drying oven during 24 hours, they are crushed with mortar and finally filtered with sieve of $0,6 \mathrm{~mm}$ (the choice of the sieve was imposed by the instructions of use of Mastersizer). Granulometric analysis was made using laser particlemeasurement instrument Mastersizer Malvern. The results obtained show that the granulometry of samples 1 and 2, close to the dam is between 0,1 and $40 \mu \mathrm{m}$. It varies between 0,1 and $100 \mu \mathrm{m}$ for samples 3,4 and 5 . The $\mathrm{d}_{50}$ varies between 2,39 and $5,07 \mu \mathrm{m}$ for all samples. The clay fraction varies between 42,8 and $64,6 \%$. The weakest fraction of clay and the strongest sand fraction are in sample 3 , the remainder of materials is as a majority of silts (figure 2).

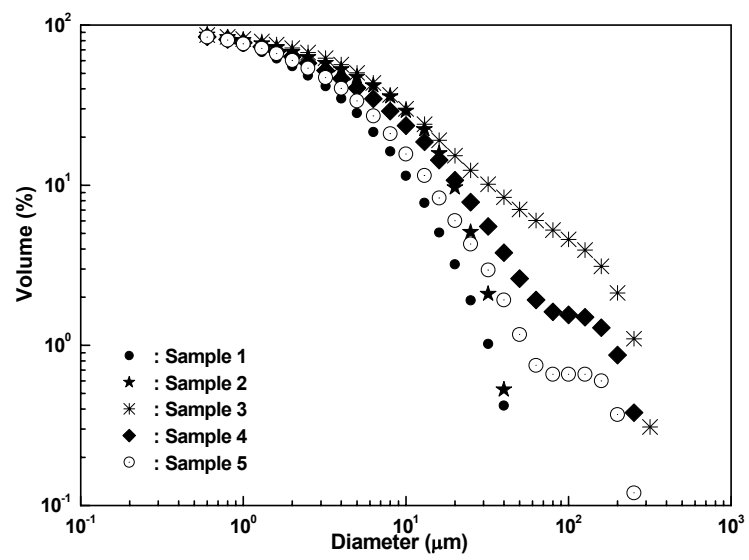

Figure 2: Granulometric curves of five samples.

The studied samples were analyzed using an electron microscope with sweeping, in order to highlight the various types of clays. The five examined samples show the presence of interstratified clays, of Smectites $(1 / 2 \mathrm{Ca}, \mathrm{Na})$, 0.7( $\mathrm{Al}, \mathrm{Mg}, \mathrm{Fe}), 4(\mathrm{Si}, \mathrm{Al}), 8\left(\mathrm{O}_{2}\right), \mathrm{n}\left(\mathrm{H}_{2} \mathrm{O}\right)$ in abundance, of detrital Quartz $\left(\mathrm{SiO}_{2}\right)$, detrital Illites and phytoclastes. The Analysis with $\mathrm{x}$-rays showed moreover the presence of carbonates: Calcite, $\mathrm{CaCO}_{3}$ and Dolomie, $\mathrm{Ca} \mathrm{Mg}\left(\mathrm{CO}_{3}\right)_{2}$, detrital Illite, badly crystallized Kaolinite and Chlorite. 
The results found by Migniot [1], show that the pelitic sediments $(\mathrm{d}<30 \mu \mathrm{m})$ which constitute the studied samples of the silt of the Wadi Fodda dam, consist of Kaolinite, Illite, Montmorillonite and Chlorite.

\subsection{Zetametry}

The samples were prepared from the mud in a natural state and water of the dam. This water was used under the same natural conditions. Thus, the prepared five samples are put in a centrifugal machine to collect the five supernatants of them. To study the variation of the Potential Zeta according to the $\mathrm{pH}$, two parts for each sample are used, of which one will be used to increase the $\mathrm{pH}$ by adding Soda $(\mathrm{NaOH})$ and the other to decrease the $\mathrm{pH}$ by adding Hydrochloric acid $(\mathrm{HCl})$. Figure 3 shows the variation of the potential zeta according to the $\mathrm{pH}$ only for two samples (samples 1 and 4). In the interval of $\mathrm{pH}$ between 6 and 10, the potential zeta varies slightly, which constitutes a stability zone. For the values of $\mathrm{pH}$ higher than 10, the potential zeta increases strongly, which constitutes a zone of non-stability. The evolution is the same for the other samples.

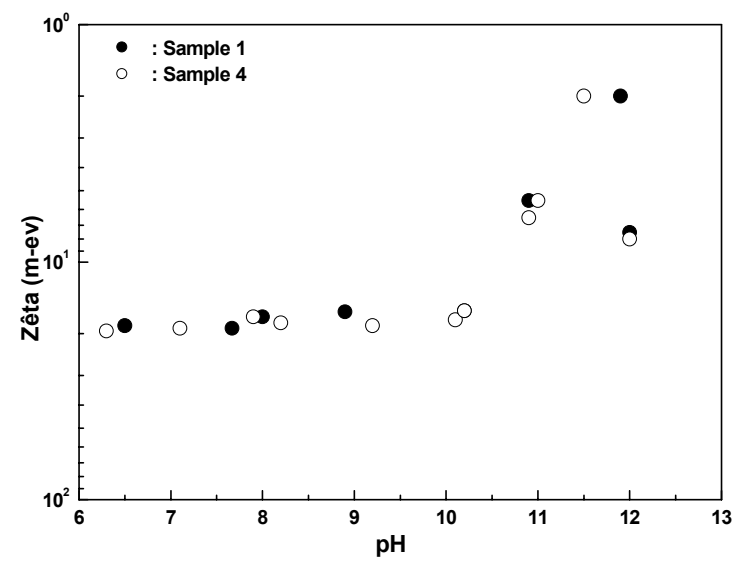

Figure 3: $\quad$ Variation of potential Zeta versus $\mathrm{pH}$ for samples 1 and 4.

\section{Yield stress of flow}

Yield stress of flow was measured by mean of the scissometry by using a scissometer (Haake VT 550). The advantage of the use of this rheometer is its mobility, its simplicity of use of the tools and the speed of its cleaning. The measurement principle is as follows:

A tool formed by two blades $0,5 \mathrm{~mm}$ of thickness, a crossed rectangular type with $90^{\circ}$ forming a brace of height $\mathrm{H}=18,9 \mathrm{~mm}$ and a diameter $\mathrm{D}=10,0 \mathrm{~mm}$. This tool is connected to a couple of sensors. This last one is plunged slowly in a container containing the sample already prepared with a well defined 
concentration in solid particles. The tool is put in rotation at a given very low angular velocity allowing the detection of the yield stress and the exerted couple is registered. For a given couple $\mathrm{C}$, the value of the stress is obtained using the following equation:

$$
\tau=\frac{C}{\pi \cdot \frac{D^{3}}{2} \cdot\left(\frac{H}{D}+\frac{1}{3}\right)}
$$

With starting, the stress increases linearly with the time, which corresponds to an elastic strain of material. A deviation occurs compared to this linearity leading to a maximum of stress, which corresponds to the flow yield stress (figure 4).

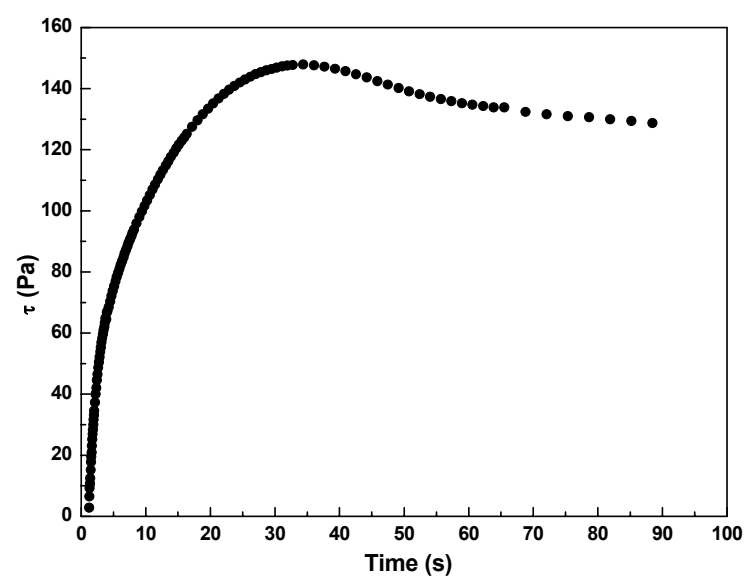

Figure 4: Determination of yield stress.

The advantage of this method is the elimination of slip phenomenon, frequently encountered with other conventional geometries of measurements in shearing.

By analyzing of granulometry curves of five studied samples, we note that the more the sample contains argillaceous particles the more is its yield stress important. Sample 3, which contains less argillaceous particles, presents a weak yield stress. These results confirm the studies carried out by Mignot [1] about the influence of various percentages of sand in the silt (5 to $30 \%$ ) on the yield stress, when we consider a total concentration (silt + sand). Each sample was prepared by adding a given quantity of water in order to have a beforehand defined concentration. All the samples were prepared the same day. The temperature was about $20^{\circ} \mathrm{C}$.

\subsection{Influence of the concentration}

Figure 5 represents the effect of the volumetric concentration on the yield stress of flow for the five samples. We note that the yield stress increases very quickly 
with the concentration for each sample. We can estimate for all the four samples $(1,2,4$ and 5$)$ that the yield stress varies between the eighth and the ninth power of the concentration $C_{v}$ :

$$
\tau=2,15 \times 10^{-11} \cdot C_{V}^{8,6}
$$

For the third sample, which contains a percentage of sand, it is difficult to have a number of sufficient points, in order to give an interpretation. On the other hand, the results found by Mignot [1] show that the yield stress varies between the fourth and the fifth power of the concentration $C_{v}$ :

$$
\tau=6,49 \times 10^{-7} \cdot C_{V}^{4,96}
$$

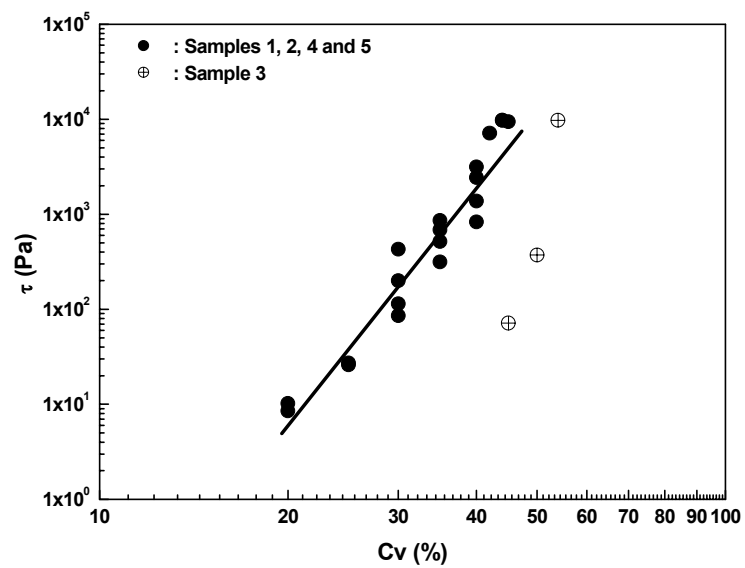

Figure 5: Variation of yield stress versus volumetric concentration.

If the lines obtained previously are prolonged on the axis of the concentrations (figure 5). We note that the yield stress is null for a concentration of 5\% for sample 5; of $10 \%$ for samples 1,2 and 4 and of $30 \%$ for sample 3 . This observation is confirmed since for sample 3, the yield stress could not be measured for concentrations lower than $40 \%$ because of the presence of sand, on the other hand for sample 5 the yield stress was measured for a concentration of $20 \%$.

\subsection{Influence of $\mathrm{pH}$}

To study the influence of the $\mathrm{pH}$ according to the yield stress, two concentrations of sample 1 and one concentration of sample 4 were prepared with the natural $\mathrm{pH}$. Each preparation is shared into two. In the first, we increase the $\mathrm{pH}$ by using the sodium hydroxide $\mathrm{NaOH}$, for the second we decreases the $\mathrm{pH}$ with hydrochloric acid $(\mathrm{HCl})$. 
Figure 6 shows that the evolution of the yield stress according to the $\mathrm{pH}$ is weak between 6 and 10 (range where the potential is minimal) and increases in a very clear manner starting from a $\mathrm{pH}$ equal to 10 . This observation is clearer especially for weak concentrations $\left(C_{v}<20 \%\right)$. It implies the close dependence of the nature of flow with the physicochemical structure of the mixture.

We note that the variation of the potential zeta according to the $\mathrm{pH}$ is compatible with the variation of the flow yield stress according to the $\mathrm{pH}$.

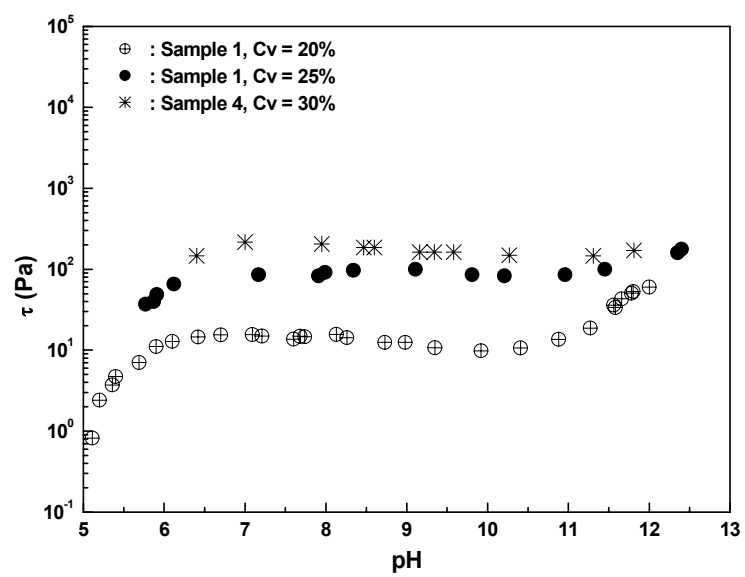

Figure 6: Variation of shear stress versus $\mathrm{pH}$.

The results obtained by Benna et al [6] by using a Brookfield rheometer for silts Wyoming (WP) and Haidoudi (HP), show a great stability of the shear stress according to the $\mathrm{pH}$ for various rotational speeds, respectively in the ranges of $\mathrm{pH}$ between 4 and 9 for the first and between 5 and 9 for the second.

\subsection{Influence of rest period}

We note that for rest periods lower than 1 hour, the yield stress does not change. From the duration of 2 hours, the increase of the yield stress starts. From the duration of 3 hours, the increase is clear (figure 7).

\section{Flow in sample shearing}

\subsection{Rheometric procedure}

The Rheometer used is Weissenberg, which works with imposed kinematic. It allows to make starting tests and to establish flow curves in steady state.

To study the flow, a preliminary study was made for the choice of the measurement geometry by using full cone-plan. We noted that the points are distributed in a random way, which shows that these results are not precise.

This inaccuracy is surely due to the dimension of the air-gap $(570 \mu \mathrm{m})$, which does not allow a free displacement of the sample, whose particles dimensions can reach $100 \mu \mathrm{m}$. 


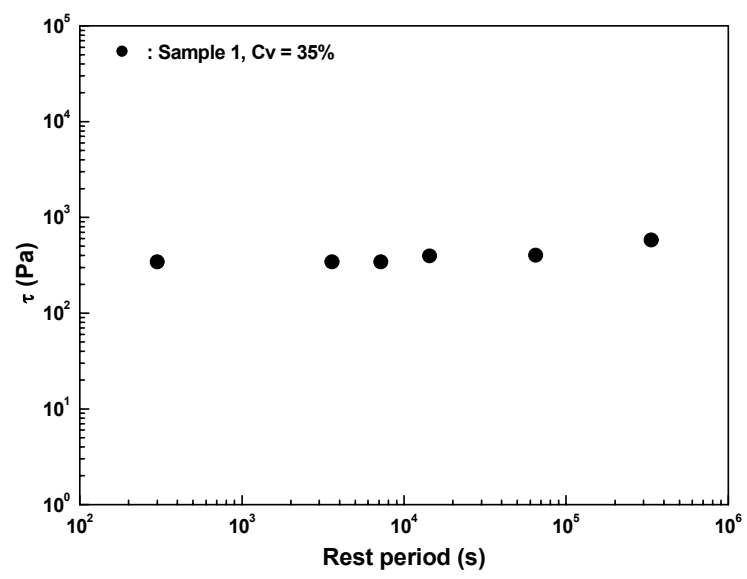

Figure 7: Variation of yield stress versus rest period.

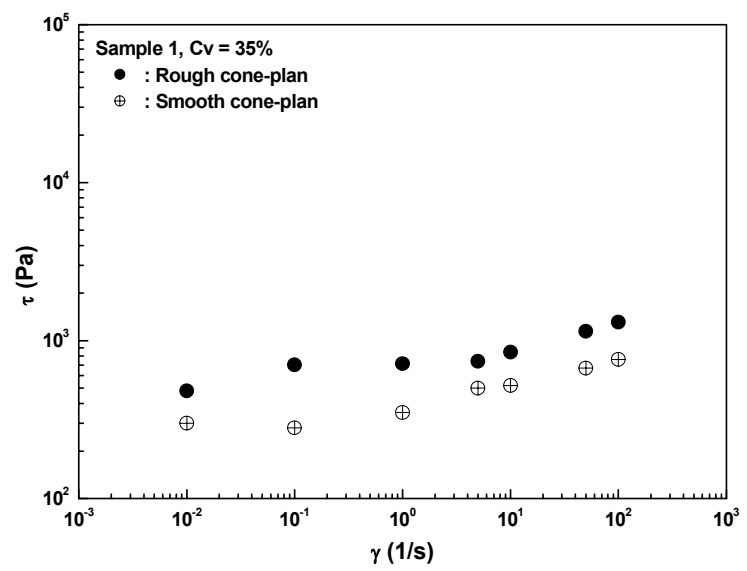

Figure 8: Influence of roughness in the case of geometry cone-plan.

There is possibility of wedging of the particles. For the tests carried out with the smooth cone-plan, we notice that the values of the stress are lower than those given by the geometry rough cone-plan (figure 8).

This difference is due to the slip with the wall of the sample. This slip was observed by a visualization using a video camera (figure 9).

During the study of 3 concentrations, we have visualized the samples under same conditions as slip. We noted that the fracturing is present in the middle of the sample for low shearing speeds lower than $1 \mathrm{~s}^{-1}$.

The obtained values of stress using couette geometries (coaxial cylinders) are near those found by the rough geometry cone-plan (figure 10). However, this geometry is not advised for practical reasons.

After all these tests, the choice was made on hollow and rough cone-plan geometry, with depends on other geometries. 


\subsection{Rheological behaviour}

On figure 11, the curves of shear stress $\tau$ as function of shear rate $\gamma$ for three concentrations of sample 1 are shown.

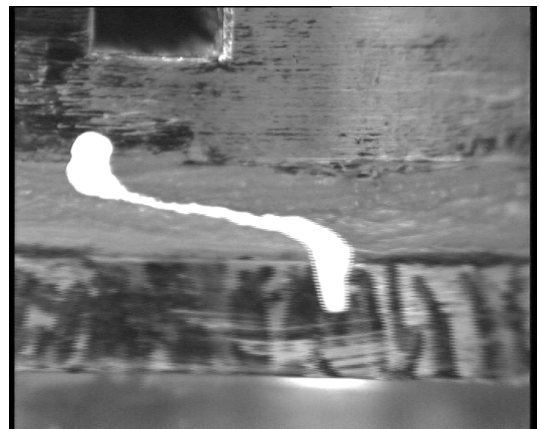

a)

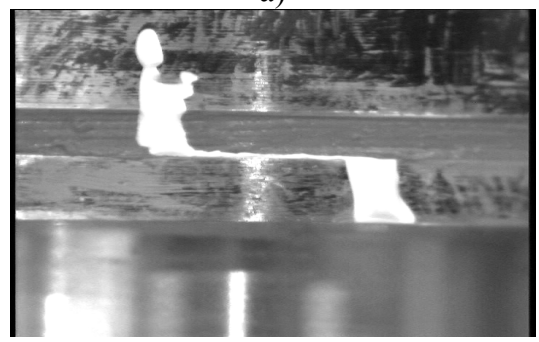

b)

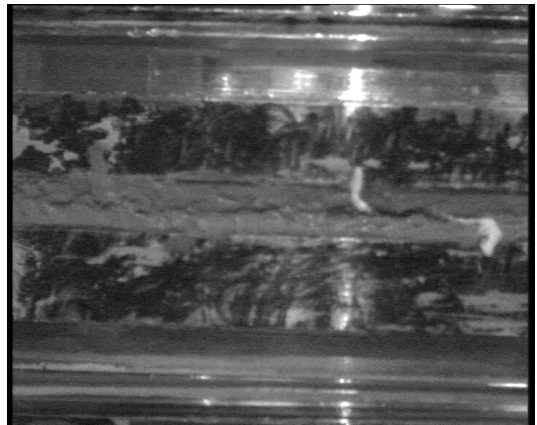

c)

a) Flow of sample for shearing speed of $50 \mathrm{~s}^{-1}, C_{v}=30 \%$ in the case of geometry rough cone-plan.

b) Fracturing of sample for shearing speed of $0.1 \mathrm{~s}^{-1}, C_{v}=30 \%$ in the case of geometry rough cone-plan.

c) Slip of sample for shearing speed of $1 \mathrm{~s}^{-1}, C_{v}=30 \%$ in the case of geometry smooth cone-plan.

Figure 9: Visualization of the flow in sample shearing.

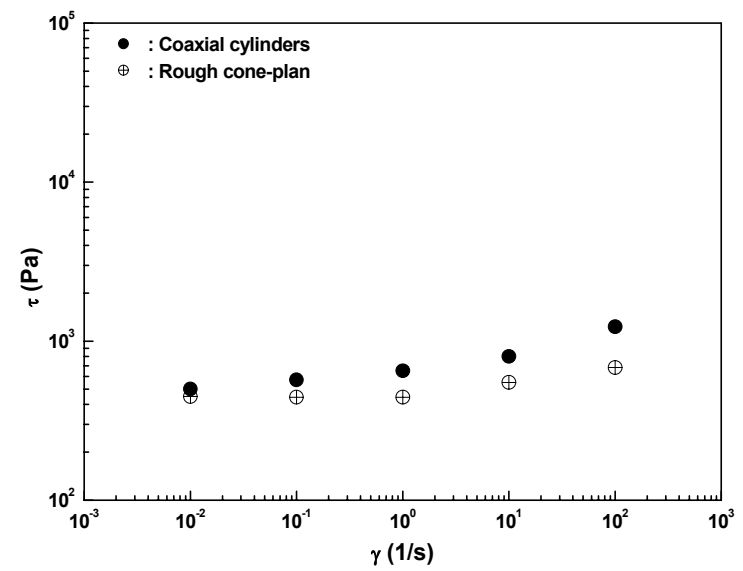

Figure 10: Influence of the geometry coaxial cylinders and rough cone-plan. 
For other samples, the results are similar. We note that the three curves have the same form and that the shear stress increases according to the concentration.

These curves are fixed on the model of Herschel-Bulkley, whose expression is as follows:

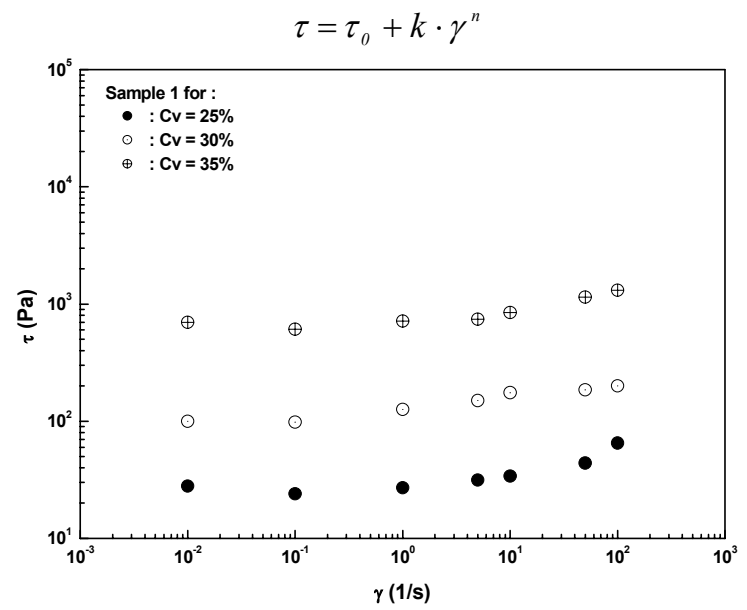

Figure 11: Variation of the shear stress versus shearing speed for sample 1.

\section{Conclusions}

In the light of modern techniques of measurements of physicochemical and rheological properties, reliable data have been measured. Granulometric analysis shows that the dimension of the particles varies between 0,1 and $100 \mu \mathrm{m}$. The fraction of clay is very important; it exceeds $50 \%$ for all the studied samples. Chemical analysis shows that the clay of the dam Wadi Fodda consists of Smectites in abundance, detrital Quartz, Illites detrital and Phytoclastes. Flow yield stress is a very important characteristic in unsilting of dams and was particularly studied by scissometry. The yield stress evolves considerably with the volumetric fraction. A great compatibility is observable between the results found for yield stress of constraint according to $\mathrm{pH}$ and those of the variation of Zeta potential according to $\mathrm{pH}$. In the range of investigated shearing rates, the rheological behavior of the studied samples is adjusted by the model of Herschel-Bulkley, where all mechanical parameters increase with the volumetric concentration of the solid.

Finally, physicochemical and rheological characteristics of the silts of the dam Wadi Fodda are highlighted. The results found and analyzed can serve as help for the study of unsilting of the dam reserve, in order to preserve the useful volume, which is essential for the needs of the area and to the national economy. These results can also be used to find effective means for the use of this mud in fields of agriculture, of construction and of industry, in order to reduce the costs of unsilting on one hand and on the other hand to avoid the rejection of million 
tons of silt downstream of the dam, which cause filling of rivers and ecological disasters. For the valorization of this silt, samples were studied at development research center of Sonatrach of Boumerdes in Algiers. These samples are molten using Tetraborate, Lithium or Sodium. The first results show that at a temperature approximately of $1050^{\circ} \mathrm{C}$, these samples are transformed into very homogeneous pastille or vitreous pearls.

\section{References}

[1] Migniot C. "Etude des propriétés physiques de différents sédiments très fins et leur comportement sous des actions hydrodynamiques". La houille blanche. Vol. 1, p. 591-620 (1968).

[2] Périgaud C., "Mécanique de l'érosion des vases". La houille blanche $\mathrm{N}^{\circ} 3$, p. 501-512 (1994).

[3] Magnin A., Piau J. M. "Cone and plate rhéometry of yield stress fluids. Study of an aqueous gel”. J. non Newtonian fluid mech., 36, 85-108 (1990).

[4] Belhadri M., "Etude des pertes de charges lors du transport des vases en conduites linéaires horizontales". Thèse de Magister. USTO (1988).

[5] Ayadi A., "Ecoulement à surface libre des boues argileuses". Thèse de Doctorat de l'Université Joseph Fourrier. Grenoble (1996).

[6] Benna M., Kbir-Arguib N., Magnin A and Bergaya F., "Effect of pH on rheological properties of purified sodium bentonite suspensions". Journal of colloid and interface science 218, 442-455 (1999).

[7] Coussot P., Boyer S. "Determination of yield stress fluid behaviour from inclined plane test". Rheol. Acta., 34, 534-543 (1995).

[8] Coussot P., Piau J.M. "On the behavior of fine mud suspensions". Rheol. Acta, 33, 175-194 (1994).

[9] Belhadri M., "Ecoulement des fluides à seuil aux travers des singularités convergentes et divergentes". Thèse de Doctorat INPG (1996).

[10] Belhadri M., "Rheology and pressure loss measurements of silt samples extracted from a dam reservoir". WIT Transactions on Ecology and the Environment, Vol. 90, 109-118 (2006)

[11] Delgado F., Gongalez-Caballero F. and J. M. Bruque, "On the Zeta potential and surface charge density of montmonrillonite in aqueous electrolyte solutions". Journal of colloid and interface science, Nov 1985.

[12] Migniot C., "Action des courants, de la houle et du vent sur les sédiments". La houille blanche. Vol. [1] 1, p. 9-47 (1977).

[13] Pignon F., "Rhéologie des dispersions aqueuses thixotropes d'une argile de type hectorite". Thèse de Doctorat INPG (1996).

[14] Coussot P., "Modélisation numérique des écoulements de laves torrentielles". La Houille Blanche, Vol. 3, pp. 50-56 (1994). 